\title{
Brownian Motion and Coagulation Process
}

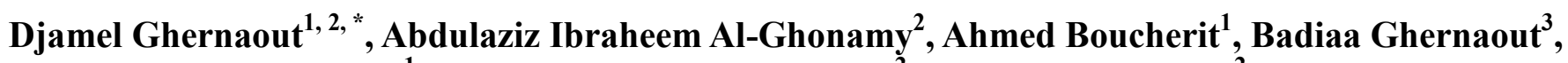 \\ Mohamed Wahib Naceur ${ }^{1}$, Noureddine Ait Messaoudene ${ }^{2}$, Mohamed Aichouni ${ }^{2}$, \\ Ammar Abdallah Mahjoubi ${ }^{2}$, Noureddine Ali Elboughdiri ${ }^{2}$ \\ ${ }^{1}$ Department of Chemical Engineering, University of Blida, Blida, Algeria \\ ${ }^{2}$ Binladin Research Chair on Quality and Productivity Improvement in the Construction Industry, College of Engineering, University of Hail, \\ Ha'il, Saudi Arabia \\ ${ }^{3}$ Department of Mechanical Engineering, University of Laghouat, Laghouat, Algeria
}

\section{Email address:}

djamel_andalus@hotmail.com

\section{To cite this article:}

Djamel Ghernaout, Abdulaziz Ibraheem Al-Ghonamy, Ahmed Boucherit, Badiaa Ghernaout, Mohamed Wahib Naceur, Noureddine Ait Messaoudene, Mohamed Aichouni, Ammar Abdallah Mahjoubi, Noureddine Ali Elboughdiri. Brownian Motion and Coagulation Process. American Journal of Environmental Protection. Special Issue: Cleaner and Sustainable Production. Vol. 4, No. 5-1, 2015, pp. 1-15. doi: $10.11648 /$ j.ajeps.s.2015040501.11

\begin{abstract}
This review discusses the Brownian motion and coagulation/flocculation $(\mathrm{C} / \mathrm{F})$ in water/wastewater treatment. In water/wastewater treatment processes, pertinent questions relating to Brownian motion and $\mathrm{C} / \mathrm{F}$ are often asked. Some of these questions are: Brownian motion and molecular agitation are favourable or not to separation processes? As high salinity (seawater) decreases disorder, increasing surface water salinity would be a convenient water treatment process or not? The processes of $\mathrm{C} / \mathrm{F}$ are used to remove dissolved substances and colloids from water in order to assure efficient settling.
\end{abstract}

Keywords: Colloid, Brownian Motion, Coagulation, Flocculation, Water/Wastewater Treatment

\section{Introduction}

In water treatment engineering, some questions are asked: Brownian motion and molecular agitation are favourable or not to separation processes? After coagulation/flocculation $(\mathrm{C} / \mathrm{F})$ and settling, two separate phases (limpid water + mud) are present, disorder is minimised or not? Freezing decreases disorder or not? Freezing treats or not water? High salinity (seawater) decreases disorder or not? Increasing surface water salinity would be a convenient water treatment process or not? In other words, this review tries to find links between Brownian motion and coagulation.

The processes of $\mathrm{C} / \mathrm{F}$ are used to remove dissolved substances and colloids from water in order to assure efficient settling $[1,2]$.

\section{Colloids}

Colloidal particles are defined as aggregates of atoms and/or molecules; their density is near to water density $(\sim 1)$ and their diameters are small enough that gravity is not able to settle them. Consequently, they remain in suspension [3]; this is why they are called stable dispersions [4]. Their stability originates from the reciprocal repulsion between colloids [5]. However, their stability may be disturbed by applying some chemical products. Coagulation is defined as the key unit process where such reactants are injected in order to destabilise the colloids repulsion, thus pushing them to form bonds together [6]. This chemical process is usually encountered before the unit operation of flocculation [7]. The colloids are frequently responsible of the turbidity and sometimes of the colour that make water undrinkable; consequently, these fine particles should be completely eliminated from water [8].

This section reviews some prerequisite topics, which are indispensable in the comprehension of $\mathrm{C} / \mathrm{F}$ process, including behaviour and stability of colloids and Zeta potential $[8,9]$.

\subsection{Colloid Behaviour}

In its great fraction, the suspended solids in surface waters are constituted with materials, such as silica, with density of 2.65 [10]. As their sizes are ranged from 0.1 to $2 \mathrm{~mm}$, they may be easily removed from water by settling. On the other hand, when their diameter is less than $10^{-5} \mathrm{~mm}(10 \mu \mathrm{m})$, they 
require sometimes a year to settle only $1 \mathrm{~mm}$. Moreover, when a particle is in this size range, we may assist to the appearance of the turbidity and/or colour of water, rendering the water unpotable. The elimination of colloids by decantation is always applicable in the case if their settling velocity is relatively rapid, i.e., some meters per hour. For these reasons, $\mathrm{C} / \mathrm{F}$ process acts by disturbing the reciprocal repulsions between colloids pushing them to form bonds together and constitute agglomerates for efficient decantation [6]. Colloids may be classified in the diameter interval of $\mathrm{nm}$ to $\mu \mathrm{m}$. Colloids are considered as agglomerates of some hundreds of atoms and/or molecules, even if a distinguished molecule, e.g., in the case of proteins, is big enough to be classified as a colloidal particle $[4,8]$.

A colloidal suspension is constituted with two phases: (1) the dispersed phase, or the solute, and (2) the dispersion medium, or the solvent [4]. Each phase can possess all the three states of matter, i.e., solid, liquid, and gas. As an illustration, we may have the dispersion medium as a liquid, and the dispersed phase as a solid. This suspension is known as a liquid sol. Sometimes, the dispersion medium is a gas and the dispersed phase is a solid. This system is known a gaseous sol, and the best illustrations are dust and smoke. Table 1 presents the various types of colloidal constitutions. In the $\mathrm{C} / \mathrm{F}$ process, in the case of water/wastewater, attention will be accorded to the solid being dissociated in water $[6,11]$. Sols may be classified as lyophilic or lyophobic; the first ones are those that constitute bonds with the solvent and the second ones are those that do not constitute bonds with the solvent. If the solvent is water, lyophilic and lyophobic sols are, respectively, named hydrophilic and hydrophobic sols. The affinity of the hydrophilic sols for water is attributed to polar functional groups that are found on their surfaces. These groups include such polar groups as $-\mathrm{OH},-\mathrm{COOH}$, and $-\mathrm{NH}_{2}$. They are, respectively, named the hydroxyl, carboxylic, and amine groups. As established, the functional polar groups are found sticking out from the surface of the particle. Due to the affinity of these groups for water, the water is attached on the surface. This water is named fixed water and is attached on the surface and moves with the colloid. On the other hand, the hydrophobic colloidal particles do not have affinity for water; consequently, they do not contain any attached water. Habitually, inorganic colloidal particles are hydrophobic, and organic ones are hydrophilic [4]. As an illustration of an inorganic colloid is the case of clay colloids that produce turbidity in water, and an illustration of an organic colloidal particle is the colloids in domestic sewage [8].

Table 1. Types of colloids [8].

\begin{tabular}{llll}
\hline Dispersion Medium & Dispersed Phase & Common Name & Example \\
\hline Solid & Solid & Solid sol & Coloured glass and gems, some alloys \\
Solid & Liquid & Solid emulsion & Jelly, gel, opal $\left(\mathrm{SiO}_{2}\right.$ and $\left.\mathrm{H}_{2} \mathrm{O}\right)$, pearl $\left(\mathrm{CaCO}_{3}\right.$ and $\left.\mathrm{H}_{2} \mathrm{O}\right)$ \\
Solid & Gas & None & Pumice, floating soap \\
Liquid & Solid & Liquid sol & Turbidity in water, starch suspension, ink, paint, milk of magnesia \\
Liquid & Gas & Foam & Whipped cream, beaten egg whites \\
Gas & Solid & Gaseous sol & Dust, smoke \\
Gas & Liquid & Gaseous emulsion & Mist, fog, cloud, spray \\
Gas & Gas & Not applicable & None \\
\hline
\end{tabular}

\subsection{Zeta Potential}

The repulsive property of colloids generates from the electrical forces that they possess [4]. At a near point from the colloid surface, the force is significant. It decreases near to zero at a high gap from the colloid. The electrical forces are generated because of the charges that the colloids have at their surfaces. These charges, named primary charges, are generated following one or both of two processes: (1) the rupture of the polar groups and (2) preferential adsorption of ions from water. The primary charges on hydrophobic colloids are attributed to preferential adsorption of ions from water [8].

The primary charges, on hydrophilic colloidal particles, are mainly attributed to the polar groups, e.g., the carboxylic and amine groups [4]. The phenomenon monitoring the charges apparition on these types of colloidal particles is shown in Fig. 1. The symbol $R$ shows the colloidal particle entity. The colloidal particle is illustrated at the top of the drawing, without the influence of $\mathrm{pH}$. By a convenient combination of the $\mathrm{H}^{+}$and $\mathrm{OH}^{-}$being introduced to the suspension, the colloidal particle achieves ionisation of carboxylic and the amine groups. At this point, both ionised groups neutralise each other and the colloid is considered as neutral. This point is well known as the isoelectric point, and the related ion of the colloid is named the zwitter ion. When $\mathrm{pH}$ is augmented by introducing a base, the added $\mathrm{OH}^{-}$will neutralise the acid extremity of the zwitter ion (i.e., the $\mathrm{NH}_{3}{ }^{+}$); the zwitter ion will disappear, and the entire colloidal entity will be negatively charged. The inverse situation is correct if the $\mathrm{pH}$ is decreased by the introduction of $\mathrm{H}^{+}$ions. The injected $\mathrm{H}^{+}$ions neutralise the base extremity of the zwitter ion (the $\mathrm{COO}^{-}$); the zwitter ion disappears, and the entire colloidal entity will be positively charged. From this interpretation, a hydrophilic colloid can reach a primary charge of either negative or positive as a function of the $\mathrm{pH}$ [12]. The first electrical charges on a colloidal particle which, as we have established, could either be classified as positive or negative, attract ions of opposite charges from the suspension. These ions with opposite charges are named counterions. This is phenomenon shown in Fig. 2. When the primary charges are enough large, the attracted counterions can constitute a compact layer surrounding the first charges. This layer is named the Stern layer. In turn, the counterions have the possibility to attract their own counterions, the coions of the primary charges, constituting an additional layer. Because these coions 
constitute a continuous distribution of ions into the bulk of the suspension, they have tendency to be distributed; moreover, they may constitute a diffused layer. The second layer is well known as the Gouy layer. Consequently, the Stern and Gouy layers constitute an envelope of electric double layer surrounding the first charges. The totality of the electric charges in the Stern layer displaces with the colloidal particle; as a result, this layer is an attached layer. In the case of the
Gouy layer, a fraction of the layer may displace with the colloidal particle by shearing at a shear plane. There is a possibility for this layer to shear off out of the boundary of the attached Stern layer evaluated from the surface of the colloidal particle. Consequently, certain variations of the charges in the layer displace with the colloid, at the same time others do not. This plane is shown in Fig. 2 [8].

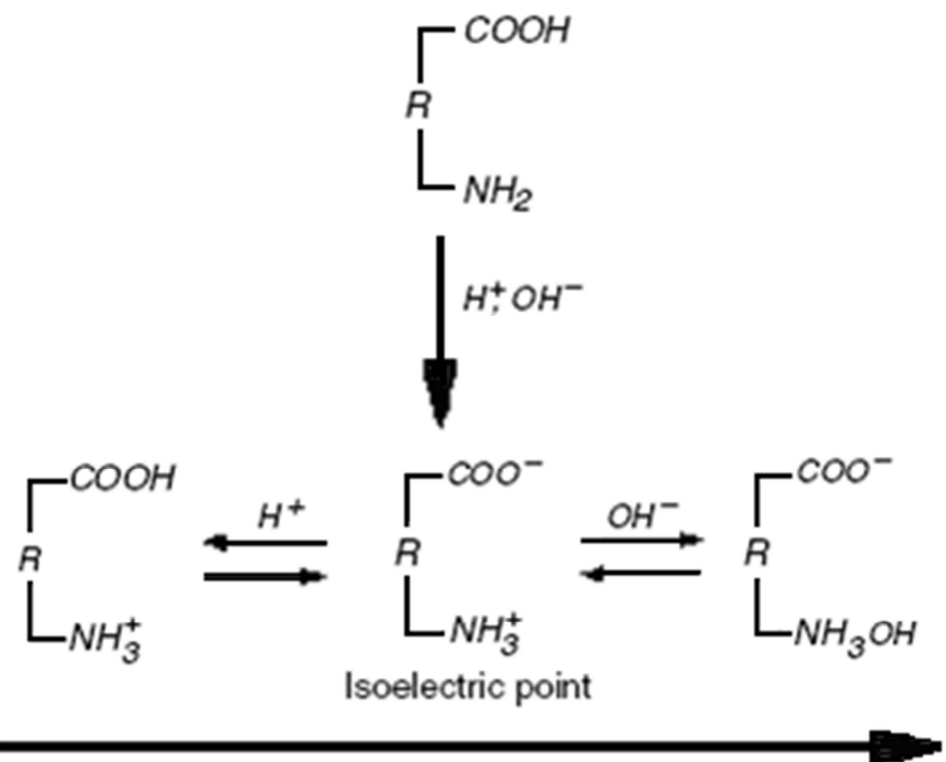

Figure 1. Initial charges of a hydrophilic colloidal particle depending on $\mathrm{pH}$ [8].
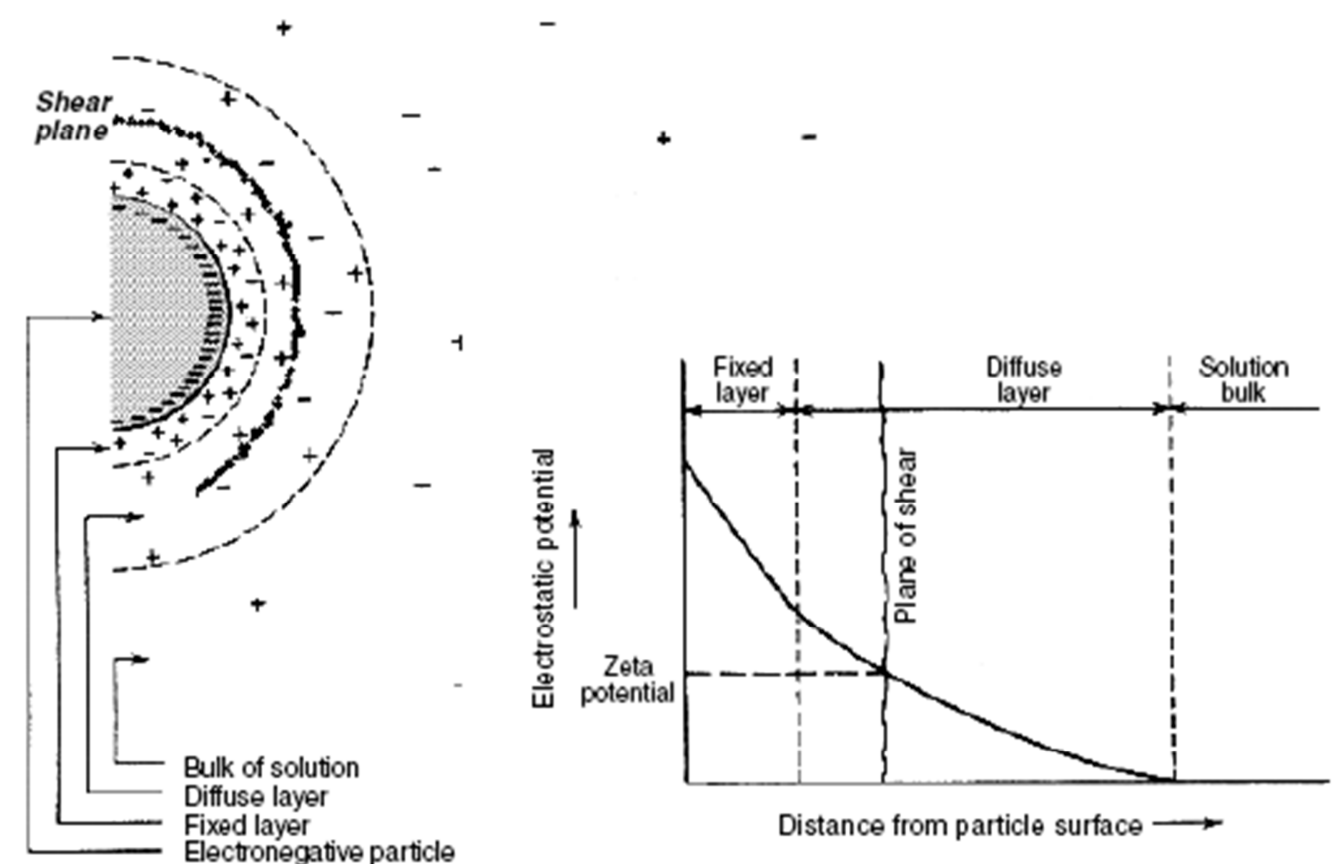

Figure 2. Charged double layer surrounding a (negatively) charged colloidal particle (left) and change of electrostatic potential as a function of distance from colloid surface (right) [8].

The electric charges possess an electrostatic potential. As shown on the right-hand side of Fig. 2, this potential is most important at the colloid surface and decreases to zero at the bulk of the suspension. The potential at a certain point from the surface at the birth of the shear plane is named the Zeta potential [4]. The greater this potential, the more important is the repulsive force and the more stable the colloidal particle [8]. 


\section{Collision Mechanisms}

Colloids are brought into contact following certain manners:

- Brownian diffusion (i.e., perikinetic agglomeration).

- Fluid motion (i.e., orthokinetic agglomeration).

- Differential sedimentation $[8,13,14]$.

These mechanisms are illustrated in Fig. 3. As seen above, all particles in water are subject to random motion as a consequence of their thermal energy. This phenomenon is well known as Brownian motion. Due to this fact, collisions between colloids produce perikinetic aggregation [15]. It is easy to evaluate the frequency of the created collisions [16]. It is evident that Brownian (perikinetic) agglomeration has not the capacity to conduct to the formation of large aggregates. This is due to the decrease in particle content and the second-order nature of the process. Practically, flocculation processes are frequently performed under conditions where the suspension is under the action of certain form of shear, i.e., by stirring or flow [17]. When colloids are transported thanks to suspension, they may produce a great influence on the rate of colloid collision. This phenomenon is named orthokinetic agglomeration [15]. In fact, the primary theoretical concept to this phenomenon was the fruit of Smoluchowski's research, at the same time with his famous study on perikinetic agglomeration [18]. In the case of orthokinetic collisions, Smoluchowski studied the example of spherical particles in uniform and laminar shear [16]. Practically, such conditions are not found; however, the simple case constitutes an appropriate basic point. Fig. 4 illustrates the primary model for the Smoluchowski analysis of orthokinetic collision intensities. Two spherical colloids, of various sizes, are fixed in a uniform shear field. This significates that the velocity of the fluid varies linearly as a function of distance in only one direction, perpendicular to the direction of flow. The rate of variation of fluid velocity in the $z$-direction is $\mathrm{d} u / \mathrm{d} z$. This is the shear rate and is attributed the symbol $G$. The centre of one colloid, radius $a_{j}$, is assumed to be fixed in a plane where the fluid velocity is zero, and colloids above and below this plane displace along fluid streamlines with various velocities, as a function of their situation. A colloid of radius $a_{i}$ will just be in contact with the central sphere if its centre lies on a streamline at a distance $a_{i}+a_{j}$ from the plane where $u=0\left(a_{i}+\right.$ $a_{j}$ is the collision radius, as in the analysis of perikinetic agglomeration) [16]. The totality of colloids at points less than the collision radius will enter in collision with the central sphere, at rates that are function of their concentration and position (and consequently velocity) [14].

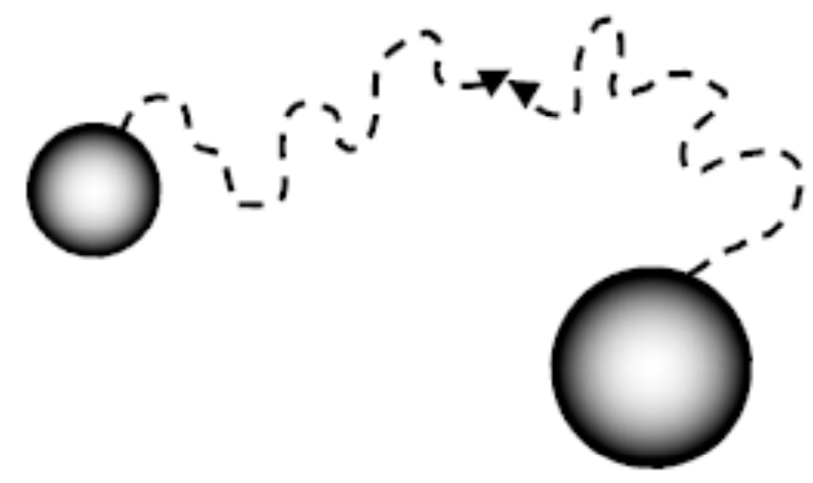

(a)

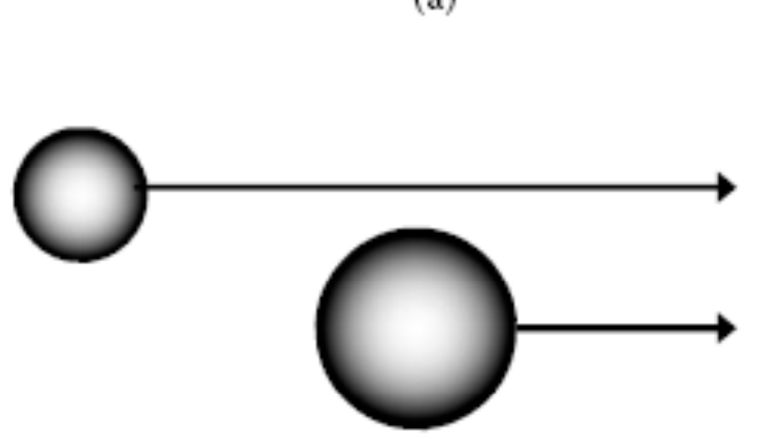

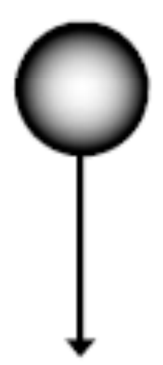

(c)

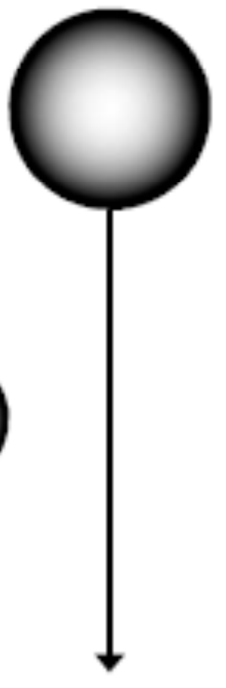

(b)

Figure 3. Particle transport conducting to collisions by (a) Brownian diffusion, (b) fluid motion, and (c) differential sedimentation [14]. 


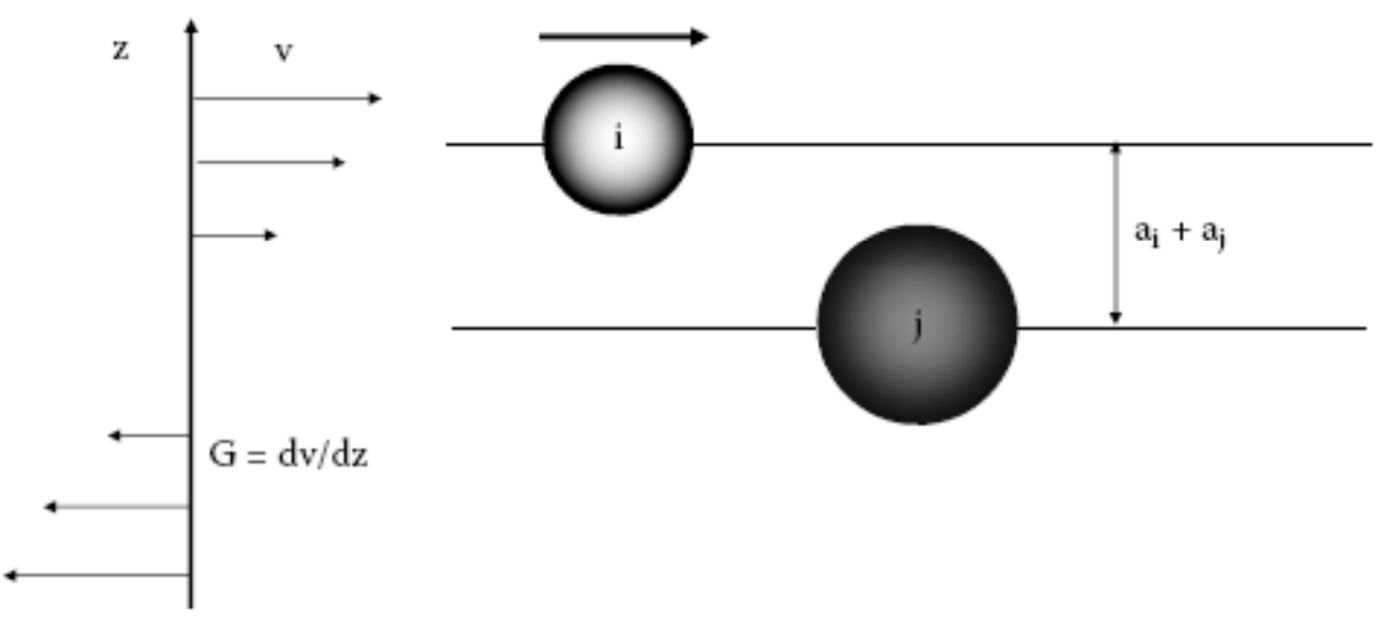

Figure 4. Model for orthokinetic agglomeration in uniform laminar shear [14].

On the other hand, there is an additional significant collision mechanism. This mechanism appears when colloids of different size (or density) are settling in water [15]. Evidently, larger and denser colloids will sediment faster and have the possibility to enter in collision with more slowly settling colloids during their settling $[13,14]$.

\section{Coagulation and Flocculation}

\subsection{Terminology}

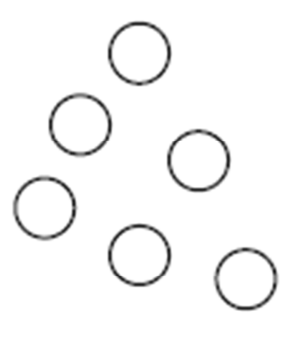

Stable
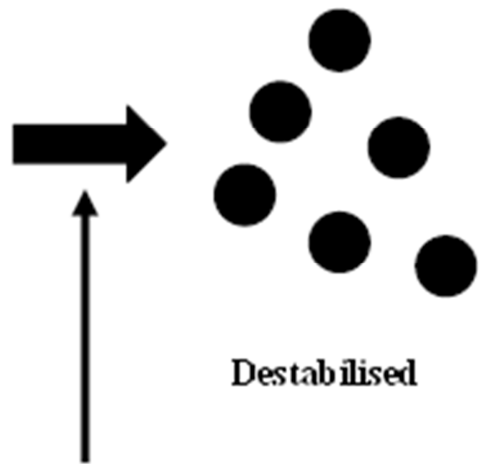

Destabilised

\subsection{1. “Coagulation" and "Flocculation"}

This section concerns processes in which suspended colloids constitute bigger agglomerates. These agglomerates can be eliminated with more efficiency by physical separation processes such as decantation and filtration [19-21]. Supposing that the colloids are originally stable, we may have two key steps in the agglomeration process. These fundamental stages are illustrated in Fig. 5:

- Destabilisation of colloids

- Collisions of colloids to build-up agglomerates [14].

\section{Add coagulant/flocculant}

Figure 5. Destabilisation and aggregation of particles [14].

We will discuss the case of stable colloids; their stability is due to their surface charge and consequently electrical double-layer repulsion [22]. In such situation, destabilisation implicates an augmentation in ionic strength or a neutralisation of the colloid charge. Introducing salts to elevate ionic strength is not considered as a convenient choice and additional additives will be utilised, as discussed in the following paragraphs. The destabilisation stage aims to render the collision efficiency, $\alpha$, as great as possible, in ideal conditions with $\alpha=1$, until the point that every collision conducts to agglomeration [15]. In the case where colloids are completely destabilised, so that $\alpha=1$, collisions are indispensable if agglomerates have to be constituted [16]. The colloid collision frequency is largely function of the particle content and of the mechanism by which collisions occur. For less concentrated water, where the frequency of the generated collisions may be insignificant, it may be easy for colloids to be completely destabilised but to demonstrate very little aggregation upon acceptable time values [16]. Due to the short-interval characteristic of interactions between particles, it is frequently easy to treat separately the destabilisation and collision phenomena [4]. That is mean that it is usually acceptable to suppose that the frequency of the generated collisions is not disturbed by interactions between colloids [14].

In the following paragraphs, the word "aggregation" will be utilised in a large sense, to significate any phenomenon whereby colloids aggregate together [23]. We may ask the 
question of other terms, particularly the largely employed words, i.e., coagulation and flocculation [24]. However, there is no wide acceptation concerning the manner, by which such words have to be utilised. Moreover, we may find at least two largely used conventions [14].

It is frequent to limit the word coagulation to situations where colloids are destabilised by salts or by charge neutralisation $(\mathrm{CN})$ and the agglomerates (coagula) have tendency to be small and dense [25]. Flocculation is consequently limited to the examples in which polymer bridging is the key stage, agglomerates have tendency to become bigger, and more open structurally [26]. Due to the fractal nature of aggregates, it is frequent that bigger structures have tendency to be more open and less dense [27]. Therefore, the differentiation between small, compact coagula and larger, less dense flocs is an unavoidable result of the stronger interparticle binding in the case of polymers, conducting to larger agglomerates [17]. An additional complication is that flocculation is, in certain conditions, applied to situations where agglomeration produces in a secondary minimum [4]. An additional quite different adoption is frequently utilised in the field of water/wastewater technology [6]. Following this convention, coagulation is related to destabilisation, by the injection of convenient chemicals, and flocculation is related to the generation of agglomerates, frequently by certain form of fluid movement (i.e., orthokinetic aggregation) [28]. These are related to the two steps illustrated in Fig. 5 and could be considered as chemical and physical characteristics of the agglomeration phenomenon [14].

\subsubsection{Destabilising Agents}

Due to the first distinction established from coagulation and flocculation, the chemical products utilised to produce destabilisation of colloids may be named coagulants or flocculants, as a function of their manner of introduction and mechanism [29]. Consequently, coagulants would be inorganic salts, including those containing specifically adsorbing counterions, and flocculants would be long-chain polymers, which implicate bridging interactions [30]. Even if there are greatly several different types of destabilising chemicals, the wide proportion of those utilised practically are classified in just two categories:

- Hydrolysing metal coagulants

- Polymeric flocculants $[31,32]$.

The type of these chemicals and their mechanism will be reviewed in the following sections [14].

\subsection{Hydrolysing Metal Coagulants}

The most largely utilised coagulants are based on aluminium and ferric salts, such as aluminium sulphate ("alum") and ferric chloride [33]. Initially, it was assumed that their mechanism was a consequence of the trivalent nature of the metals, producing $\mathrm{Al}^{3+}$ and $\mathrm{Fe}^{3+}$ ions in suspension, which are supposed to be very efficient in destabilising negatively charged particles [5]. In fact, this is a largely oversimplified consideration due to the fact that trivalent metal ions are easily hydrolysed in water, which has an important influence on their action as coagulants [14].

\subsubsection{Hydrolysis of Metal Cations}

In certain conditions, metal ions in solution are found as simple hydrated cations. This is the situation for alkali metal ions such as $\mathrm{Na}^{+}$and $\mathrm{K}^{+}$. Due to the polar nature of water, such cations are hydrated at a certain level, which significates they are surrounded by some water molecules fixed by electrostatic attraction between the positive metal ion and the negative (oxygen) extremities of the water molecules. It is acceptable to resonate in matter of a primary hydration shell, where water molecules are directly related to the central metal ion and more strongly fixed water in a secondary hydration shell. In the case of the trivalent metal ions $\mathrm{Al}^{3+}$ and $\mathrm{Fe}^{3+}$, it is established that the primary hydration shell is constituted of six water molecules in octahedral coordination (see Fig. 6 (a)). Due to the elevated positive charge on the central metal ion, electrons tend to be drawn in the direction of the metal from the water molecules, and this may conduct to the liberation of $\mathrm{H}^{+}$leaving a hydroxyl group fixed and a decreased positive charge for the metal, as illustrated in Fig. 6 (b). Since the phenomenon essentially implicates the splitting of water molecules, it is named hydrolysis. Since hydrolysis produces the liberation of $\mathrm{H}^{+}$into water, it is strongly dependent of $\mathrm{pH}$. Indeed, elevated $\mathrm{pH}$ values favour dissociation and vice versa. Moreover, as each proton is liberated, the reducing positive charge renders additional dissociation more complicated. Consequently, with augmenting $\mathrm{pH}$ there is a sequence of hydrolysis equilibria, which can be presented as follows [14]:

$$
\mathrm{M}^{3+} \rightarrow \mathrm{M}(\mathrm{OH})^{2+} \rightarrow \mathrm{M}(\mathrm{OH})_{2}^{+} \rightarrow \mathrm{M}(\mathrm{OH})_{3} \rightarrow \mathrm{M}(\mathrm{OH})_{4}^{-}(1)
$$

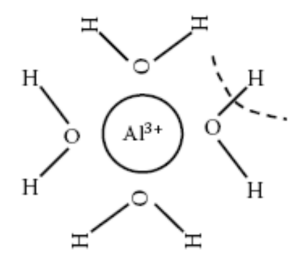

(a)

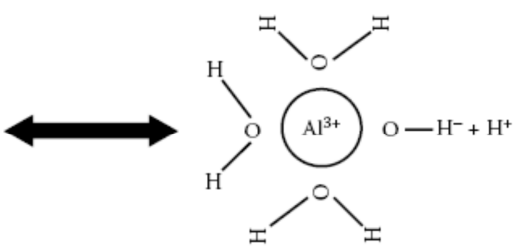

(b)
Figure 6. Hydrolysis of $\mathrm{Al}^{3+}\left[(\mathrm{a})\right.$ hydrated aluminium cation, only 4 of $6 \mathrm{H}_{2} \mathrm{O}$ molecules shown, (b) after release of $\mathrm{H}^{+}$to form $\left.\mathrm{Al}(\mathrm{OH})^{2+}\right]$ [14].

For convenience, $\mathrm{H}_{2} \mathrm{O}$ molecules, in the hydration envelop, are not presented. Each of the steps in the hydrolysis phenomenon has a convenient equilibrium constant [14]:

$$
\begin{array}{rlr}
\mathrm{M}^{3+}+\mathrm{H}_{2} \mathrm{O} & \leftrightarrow \mathrm{M}(\mathrm{OH})^{2+}+\mathrm{H}^{+} & K_{l} \\
\mathrm{M}(\mathrm{OH})^{2+}+\mathrm{H}_{2} \mathrm{O} \leftrightarrow \mathrm{M}(\mathrm{OH})_{2}{ }^{+}+\mathrm{H}^{+} & K_{2} \\
\mathrm{M}(\mathrm{OH})_{2}{ }^{+}+\mathrm{H}_{2} \mathrm{O} & \leftrightarrow \mathrm{M}(\mathrm{OH})_{3}+\mathrm{H}^{+} & K_{3} \\
\mathrm{M}(\mathrm{OH})_{3}+\mathrm{H}_{2} \mathrm{O} & \leftrightarrow \mathrm{M}(\mathrm{OH})_{4}{ }^{-}+\mathrm{H}^{+} & K_{4}
\end{array}
$$

These are defined in the classical method, so that in the situation of $K_{2}$, for example:

$$
K_{2}=\frac{\left[M(\mathrm{OH})_{2}^{+}\right]\left[\mathrm{H}^{+}\right]}{\left[\mathrm{M}(\mathrm{OH})^{2+}\right]}
$$


where square brackets represent molar concentrations of the different species [14].

For $\mathrm{Al}$ and $\mathrm{Fe}(\mathrm{III})$, the uncharged hydroxide, $\mathrm{M}(\mathrm{OH})_{3}$, has too poor solubility in water and is possibly to constitute a precipitate upon a certain interval of $\mathrm{pH}$. This precipitation is crucial in the mechanism of hydrolysing metal coagulants. As well as the equilibrium constants listed earlier, a solubility constant for the metal hydroxide is also required, considering the following dissociation of the solid phase, $\mathrm{M}(\mathrm{OH})_{3(\mathrm{~s})}$ :

$$
\begin{aligned}
\mathrm{M}(\mathrm{OH})_{3(\mathrm{~s})} & \leftrightarrow \mathrm{M}^{3+}+3 \mathrm{OH}^{-} \quad K_{s} \\
K_{s} & =\left[\mathrm{M}^{3+}\right]\left[\mathrm{OH}^{-}\right]^{3}
\end{aligned}
$$

If correct equilibrium were achieved, consequently the convenient solubility constants would be those for the stable crystalline forms such as gibbsite and goethite, in the case of $\mathrm{Al}$ and $\mathrm{Fe}$, respectively. On the other hand, these are habitually constituted slowly (usually weeks or months). Considering the point of view of coagulation process, it is much more important to deal with the solubility constants $\left(K_{\text {sam }}\right)$ of the amorphous precipitates that generate originally. However, these values are affected with some uncertainty and only evaluated values can be presented. They are frequently at least 100 -fold bigger than values for the corresponding crystalline solids; consequently, the amorphous material is soluble. Table 2 presents certain values for the hydrolysis and solubility constants for $\mathrm{Al}$ and $\mathrm{Fe}(\mathrm{III})$ species in water at $25^{\circ} \mathrm{C}$ and at zero ionic strength; consequently, they are convenient for low salt concentrations, typical of many natural waters. The constants are shown in the conventional $\mathrm{p} K$ form (where $\mathrm{p} K=$ $\left.-\log _{10} K\right)$. Using these $\mathrm{p} K$ values, it is easy to evaluate, as a function of $\mathrm{pH}$, the concentrations of the various dissolved hydrolysis products in equilibrium with the amorphous hydroxide precipitate. Due to uncertainties over the solubility constants for the amorphous precipitates, the results may not be very accurate, but they present a helpful indication of the relative significance of the different species over an interval of $\mathrm{pH}$ values. Fig. 7 is a speciation diagram illustrating the results of such evaluations for $\mathrm{Al}$ and $\mathrm{Fe}(\mathrm{III})$, considering data in Table 2. The total content of dissolved species, in equilibrium with the solid form, is really the solubility of the metal at a certain value of pH. From Fig. 7, it is obvious that there is a certain minimum solubility, which appears near neutral $\mathrm{pH}$, for both metallic forms. It must be noted here that the minimum solubility of Fe(III) is greatly lower than that of $\mathrm{Al}$ and that the minimum is widely larger. Moreover, it is clear that, for of $\mathrm{Al}$, the anionic form $\mathrm{Al}(\mathrm{OH})_{4}^{-}$(aluminate) is the predominant dissolved species near neutral $\mathrm{pH}$. An additional manner of presenting the speciation values is to plot the mole fraction of each species as a function of the total dissolved quantity in equilibrium with the amorphous hydroxide. This has been performed in Fig. 8 for $\mathrm{Al}$ and $\mathrm{Fe}(\mathrm{III})$. These results illustrate great gaps between these metals. In the case of $\mathrm{Al}$, the dominant species are $\mathrm{Al}^{3+}$, at low $\mathrm{pH}(\sim 4.5)$ and the aluminate ion, $\mathrm{Al}(\mathrm{OH})_{4}^{-}$, at $\mathrm{pH}$ values more important than $\sim 7$. The intermediate species make only minor roles at $\mathrm{pH}$ values in the interval of $\sim 4-6.5$. For Fe(III), the different species are found upon a larger $\mathrm{pH}$ interval (about 8 units) and each hydrolysis product is predominant at certain $\mathrm{pH}$ values. This is the predicted behaviour for hydrolysis of metal ions. The cause that $\mathrm{Al}$ species are "squeezed" into a much narrower $\mathrm{pH}$ interval is assumed to be the consequence of a transition from octahedral coordination in $\mathrm{Al}^{3+} \cdot 6 \mathrm{H}_{2} \mathrm{O}$ to the tetrahedral $\mathrm{Al}(\mathrm{OH})_{4}{ }^{-}$. In the situation of $\mathrm{Fe}(\mathrm{III})$, octahedral coordination is fixed throughout. Moreover, it is important to indicate that the soluble, uncharged $\mathrm{Fe}(\mathrm{OH})_{3}$ is the dominant dissolved $\mathrm{Fe}$ species in the $\mathrm{pH}$ interval 7-9 (even if the real content is only $\left.\sim 2 \times 10^{-8} \mathrm{M}\right)$. The corresponding $\mathrm{Al}$ species, $\mathrm{Al}(\mathrm{OH})_{3}$, is often a minor dissolved component in relative terms, although it is at least 10 times more soluble than $\mathrm{Fe}(\mathrm{OH})_{3}[14]$.

Table 2. Equilibrium constants ( $p K$ values) for Al and Fe(III) hydrolysis and solubility of amorphous hydroxides (values for $25^{\circ} \mathrm{C}$ and zero ionic strength) [14].

\begin{tabular}{llllll}
\hline & $\mathbf{p} \boldsymbol{K}_{\mathbf{1}}$ & $\mathbf{p} \boldsymbol{K}_{\mathbf{2}}$ & $\mathbf{p} \boldsymbol{K}_{\mathbf{3}}$ & $\mathbf{p} \boldsymbol{K}_{\mathbf{4}}$ & $\mathbf{p} \boldsymbol{K}_{\text {sam }}$ \\
\hline $\mathrm{Al}^{3+}$ & 4.95 & 5.6 & 6.7 & 5.6 & 31.5 \\
$\mathrm{Fe}^{3+}$ & 2.2 & 3.5 & 6 & 10 & 38 \\
\hline
\end{tabular}

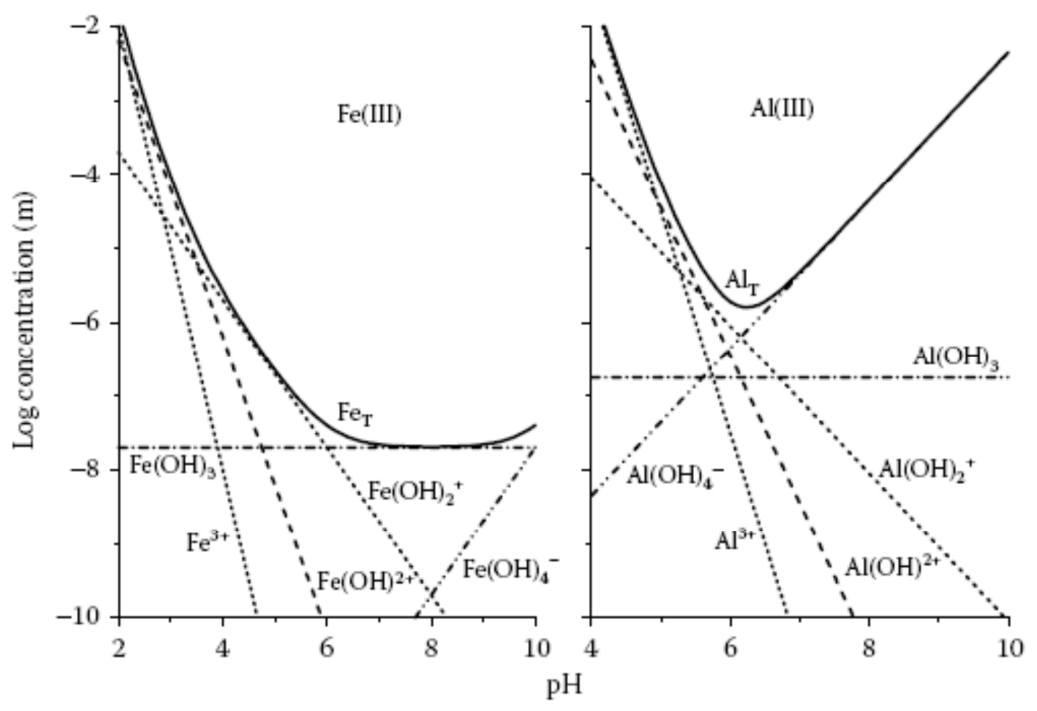

Figure 7. Speciation diagrams for Fe(III) and Al(III) (only monomeric hydrolysis products indicated) [14]. 


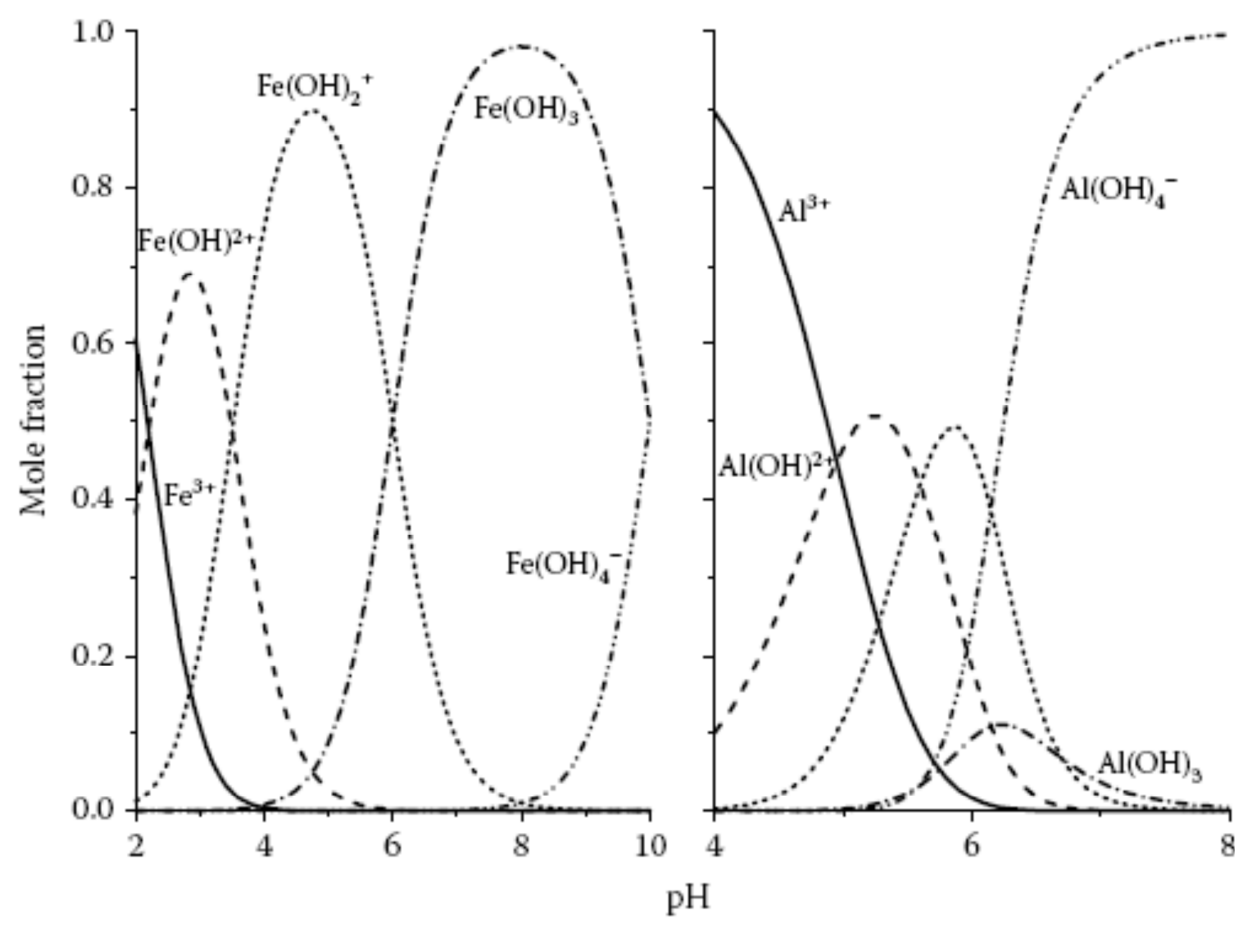

Figure 8. Proportion (mole fraction) of hydrolysed Fe(III) and Al(III) species relative to total soluble metal concentration [14].

Our review so far has not taken into consideration some difficulties. One of these difficulties is the action of different anionic species that may affect hydrolysis equilibria. As an example, it is established that fluoride constitutes strong complexes with $\mathrm{Al}$ and this generates most important aluminium solubility than would be expected based on the results in Fig. 8. Another remark is that only monomeric hydrolysis products have been taken into account, at the same time, under some conditions, polynuclear species can be significant. These constitute the subject of the next section [14].

\subsubsection{Polynuclear Hydrolysis Products}

In addition to the monomeric hydrolysis products discussed previously, there are several possible polynuclear forms that may be significant. For Al these include $\mathrm{Al}_{2}(\mathrm{OH})_{2}{ }^{4+}$ and $\mathrm{Al}_{3}(\mathrm{OH})_{4}{ }^{5+}$ [25], and there are similar forms for $\mathrm{Fe}(\mathrm{III})$ [34]. On the other hand, these may be unimportant at the low contents of the metals habitually utilised in coagulation [35]. Practically, only the monomeric products and the hydroxide precipitate may be significant. Polynuclear hydrolysis forms can be produced in some circumstances. The best encountered of these is $\mathrm{Al}_{13} \mathrm{O}_{4}(\mathrm{OH})_{24}{ }^{7+}$ or " $\mathrm{Al}_{13}$ " " which can be produced by certain neutralisation of aluminium salt solutions or by many different manners [25]. This tridecamer has the so-named keggin structure, consisting of a central tetrahedral $\mathrm{AlO}_{4}{ }^{5-}$ unit surrounded by $12 \mathrm{Al}$ octahedra with shared extremities. The tetrahedral and octahedral $\mathrm{Al}$ sites can be without difficulty distinguished in the ${ }^{27} \mathrm{Al}$ NMR spectrum. Under convenient conditions, $\mathrm{Al}_{13}$ constitutes rapidly and essentially irreversibly, remaining stable in aqueous solutions for long time. The tridecamer is assumed present largely in the natural aquatic medium (e.g., in acid forest soil water). Using coagulation data, additional polynuclear forms, such as the octamer, $\mathrm{Al}_{8}(\mathrm{OH})_{20}{ }^{4+}$, have been suggested [36]. In fact, there is no clear prove for the octamer and it is not likely to be important practically. There are several commercial chemicals based on prehydrolysed metal salts. For aluminium, a frequent example is the class of materials known as polyaluminium chloride ( $\mathrm{PACl})$, which may be formed by controlled neutralisation of aluminium chloride solutions [37]. It is possible that several of such chemicals contain significant contents of the tridecamer $\mathrm{Al}_{13}$. For aluminium sulphate, it is hard to produce prehydrolysed species with elevated degrees of neutralisation since sulphate promotes hydroxide precipitation. The presence of small contents of dissolved silica can importantly ameliorate the stability, and the resulting chemical is named polyaluminosilicate-sulphate [14]. There are corresponding products containing polymerised iron species [38], even if these are not as largely utilised as PACl [39].

\subsubsection{Action of Hydrolysing Coagulants}

In fact, there are mainly two significant manners, in which hydrolysing coagulants may destabilise and coagulate particles with negative charge [14]. At low contents and upon appropriate $\mathrm{pH}$ values, cationic hydrolysis reactants may adsorb and neutralise the colloid charge, consequently producing destabilisation and coagulation [36]. At more important concentrations of metallic salt, hydroxide precipitation appears and this has a great action - forming the so-called sweep flocculation $(S F)$ [40].

\subsubsection{Charge Neutralisation (CN) by Adsorbed Species}

At low contents of metal, only soluble species are detected (see Fig. 7). It is usually assumed that hydrolysed cationic species such as $\mathrm{Al}(\mathrm{OH})^{2+}$ are more easily fixed on negative 
surfaces than the free metal ion and so may efficiently neutralise surface charge. In a general manner, $\mathrm{CN}$ with aluminium salts appears at low metal contents, habitually of the order of a few micromoles/L at $\sim \mathrm{pH} 7$. It is known that, for many inorganic suspensions at $\mathrm{pH} 6$, the quantity of $\mathrm{Al}$ required to neutralise the surface charge is near $5 \mu$ moles per $\mathrm{m}^{2}$ of particle surface $\left(\sim 130 \mu \mathrm{g} \mathrm{Al}\right.$ per $\left.\mathrm{m}^{2}\right)$. In fact, even at very low metal contents, the solubility of the amorphous hydroxide may be surmounted. In addition, in the area of neutral $\mathrm{pH}$, cationic hydrolysis reactants represent only a small proportion of the total soluble metal, particularly for $\mathrm{Al}$ (Fig. 8). The fact that $\mathrm{CN}$ is frequently detected in such examples assumes that the efficient species might be colloidal hydroxide particles [12]. In the case of aluminium hydroxide, the point of zero charge is near $\mathrm{pH} \mathrm{8}$; consequently, the precipitate particles should be positively charged at lower $\mathrm{pH}$ values. For ferric hydroxide, the point of zero charge is lower, near $\mathrm{pH}$ 7. Moreover, when the bulk solubility is not surmounted, it is likely that certain form of surface precipitation will appear because of nucleation at the surface. Really, it is not easy to differentiate between surface precipitation and the fixation of colloidal hydroxide particles that have been precipitated in solution [12]. A combination of these effects may be most possible practically and constitutes the basis of the precipitation charge neutralisation (PCN) model, which is shown schematically in Fig. 9. Whatever the precise nature of the charge-neutralising species, they are possible to be apt of charge reversal at higher dosages; in other words, this fact significates that there will be a characteristic optimum dosage at which coagulation is most performant [36] At higher dosages, particles become positively charged and restabilised. The optimum dosage must be function of the particle concentration; however, practically the value is frequently low. In some cases, the optimum dosage interval can be limited; consequently, precise dosing control is required. Another disadvantage of relying on $\mathrm{CN}$ is that, for low particle concentrations, the collision rate and consequently the agglomeration rate will be low, and long periods may be required to give significantly large flocs [17]. Neutralising surface charge, by small-adsorbed species, does nothing to increase the collision rate, even if, of course, the collision efficiency can be importantly improved [14].

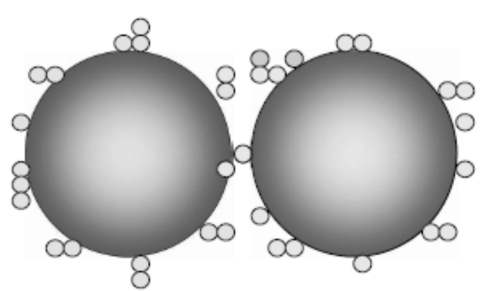

(a)

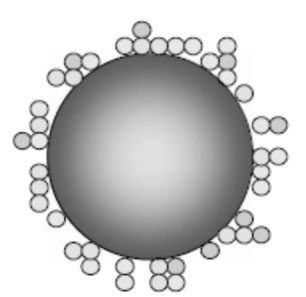

(b)
Figure 9. Precipitation charge neutralisation (PCN) model, showing (a) $\mathrm{CN}$ and (b) charge reversal (restabilisation) of particles by precipitated hydroxide colloids [14].

Some of the advantages announced for prehydrolysed coagulants are assumed to be a consequence of the presence of highly charged cationic species, such as $\mathrm{Al}_{13} \mathrm{O}_{4}(\mathrm{OH})_{24}{ }^{7+}$. The fact that this ion carries 7 positive charges assumes that it would be very strongly adsorbed on negative surfaces and would be efficient in neutralising particle charge. If we assume that species such as $\mathrm{Al}_{13}$ can be more performant in charge neutralisation, it will be difficult to see how, at the optimum dosage, the coagulation rate could be more important than with other adsorbing cationic species [14].

\subsection{5. "Sweep" Flocculation}

Practically in water/wastewater treatment operations, metal coagulants are injected at dosages much higher than the solubility of the amorphous hydroxide and extensive precipitation appears. For some causes, that are not completely accepted, this can produce much more efficient separation than simple $\mathrm{CN}$. The most possible interpretation is that the initial colloids are fixed, in a certain manner, into the growing hydroxide precipitate and are consequently eliminated from water. This enmeshment of particles is usually assumed as a "sweeping" action - consequently the term "sweep flocculation" (SF) [17]. The hydroxide precipitate could be considered as "bridging" particles together and consequently "SF" might be the more convenient term from one point of consideration [17,41]. In addition, in water/wastewater treatment, the formation of large hydroxide agglomerates needs some form of agitation; consequently, orthokinetic collisions are important, and this once again encourages the utilisation of the term "flocculation" [42]. The agglomerates constituted because of hydroxide precipitation are largely known as "flocs" [17]. However, it is confusing that the additives utilised are widely known as "coagulants" [14].

Moreover, $S F$ usually conducts to faster aggregation than $\mathrm{CN}$ and produces stronger and larger flocs [17]. It is easy to understand the reason for the higher aggregation rate [14]. The generation of a hydroxide precipitate produces a big augmentation in the efficient particle concentration and consequently a most important collision rate, following Smoluchowski theory [15]. Hydroxide precipitates are constituted from large numbers of colloids, which constitute very soon after injection [12]. The agglomeration of these colloids produces low-density flocs, with a relatively big volume [23]. Following the theory of orthokinetic aggregation, the rate is directly proportional to the volume fraction of suspended particles, and this can be largely augmented by hydroxide precipitation [43]. This is the principal explanation why $S F$ is so much more efficient than CN [44]. The flocs formed under "sweep" conditions are also stronger and consequently grow larger for the same shear conditions [23]. A great advantage of $S F$ is the fact that it does not much depend on the nature of the colloids to be eliminated, whether bacteria, clays, oxides, or others [44]. For relatively less concentrated suspensions, the optimum coagulant injection is that which produces the most rapid hydroxide precipitation and is not practically function of the nature and concentration of suspended particles. The large volume associated with hydroxide flocs conducts to an important practical problem the production of large quantities of sludge that requires to be 
removed of in certain mannert [23]. In a water treatment plant, most of the sludge generated is in bonds with metal hydroxide rather than the impurities eliminated from water. Even if there is habitually no important restabilisation in the case of $S F$ and consequently no sharp optimum dosage region, overdosing is best avoided to limit the volume of sludge generated [37].

The mechanism of prehydrolysed coagulants, such as $\mathrm{PACl}$, at typical injections also very possibly implicates hydroxide precipitation and $S F$, even if this point has not been widely studied [17,37]. There is prove that the nature of the precipitate differs from that produced with "alum" [14].

\subsubsection{Overview}

When hydrolysing coagulant is increased to a suspension of negatively charged colloids, four distinct zones are distinguished:

Zone 1: Very low dosage; colloids remain negative and consequently stable,

Zone 2: Dosage sufficient to produce $\mathrm{CN}$ and consequently coagulation,

Zone 3: Higher dosage generating charge reversal and restabilisation,

Zone 4: Still higher dosage producing hydroxide precipitation and $S F$ [14].

Fig. 10 illustrates the results of a standard jar test manner, habitually utilised in water treatment plants. In this manner, a suspension is injected with various quantities of coagulant under standard mixing and decantation conditions [13]. Habitually, there is a brief rapid mix time instantaneously after injection. This is followed by a longer time of slow stirring during which flocs may be generated because of orthokinetic aggregation [17]. Then, these flocs are authorised to settle for a standard time, after which a sample of the supernatant water is aspired and its turbidity is evaluated [23]. This residual turbidity produces a good information of the intensity of elimination during decantation and consequently of the efficiency of the $\mathrm{C} / \mathrm{F}$ process [13]. Fig. 10 illustrates that, at very low coagulant injection, the remaining turbidity is high, showing little or no sedimentation (Zone 1). As the dose is elevated, there is a narrow interval (Zone 2) where there is an important reduction in remaining turbidity. This is the area of $\mathrm{CN}$ by adsorbed species, and it is frequently found that the colloid charge (as measured, for instance, by electrophoretic mobility $[45,46]$ or streaming current [47]) is near zero. At higher injections, remaining turbidity is once again high, showing restabilisation of the colloids because of excess adsorption and charge reversal (Zone 3). Finally, at still higher dosages, there is a significant removal in remaining turbidity due to hydroxide precipitation and $S F$ (Zone 4). It should be indicated that the remaining turbidity in Zone 4 is lower than that in Zone 2, illustrating that $S F$ produces larger, faster-settling flocs than those generated by $\mathrm{CN}$ [23]. In addition, as mentioned above, there is no restabilisation after Zone 4. The behaviour illustrated in Fig. 10 is typical of aluminium salts near $\mathrm{pH} 7$ [17]. With these conditions, the hydroxide precipitate is positively charged. At $\mathrm{pH}$ values near to the isoelectric point (around $\mathrm{pH} 8$ ), Zone 2 may not be clear and only $S F$ is functioning [14].

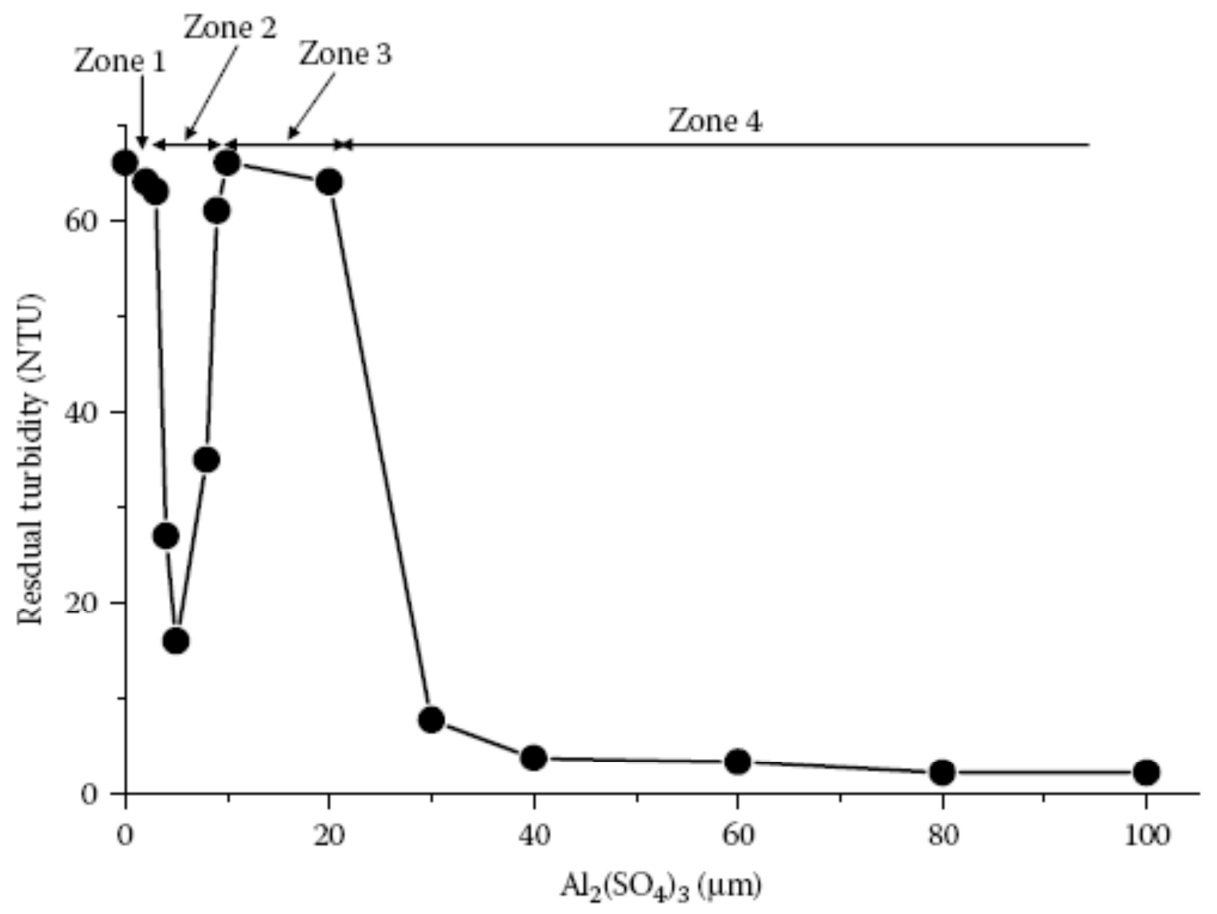

Figure 10. Residual turbidity of kaolin suspensions after coagulation with aluminium sulphate over an interval of doses at pH 7 [14].

\subsubsection{Practical Aspects}

Many important factors can importantly influence the efficiency of hydrolysing coagulants [17]. These comprise the effects of different anions and the effect of temperature [45]. Several frequent anions can constitute complexes with 
aluminium and iron (III) and can importantly influence hydroxide precipitation. An important illustration is sulphate, which is naturally present in water and may be introduced as aluminium or ferric sulphate during water treatment. Sulphate coordinates moderately strongly with $\mathrm{Al}$, but the important influence is on the precipitation process. On the positive effect of the isoelectric point of aluminium hydroxide (i.e., below about $\mathrm{pH} 8$ ), sulphate can adsorb on the precipitate and decrease its positive charge. This significates that the colloidal precipitate can agglomerate more rapidly to generate large hydroxide flocs $[14,48]$.

Temperature has influences that are practically significant [49]. Particularly, at rather low temperatures, conventional aluminium coagulants have tendency to achieve less well for different causes [45]. Some prehydrolysed coagulants seem to be less influenced by low temperatures and are usually proposed for applications in cold areas [45]. Another advantage of prehydrolysed coagulants, such as $\mathrm{PACl}$, is that, at efficient injections, they form less sludge than simple metal salts [37]. This may be partly attributed to the fact that they can be efficient at lower dosages [50]. Hydroxide flocs, as generated under $S F$, have tendency to be weak and are easily disrupted under high shear conditions [17]. In addition, the breakage can be irreversible at a certain level; consequently, flocs do not easily reform when the shear rate is decreased [14].

\subsection{Flocculation Processes}

The principal needs for efficient flocculation are as follows:

- Rapid mixing of coagulants (Fig. 11).

- Opportunity for collisions of destabilised particles and so flocculation [14].

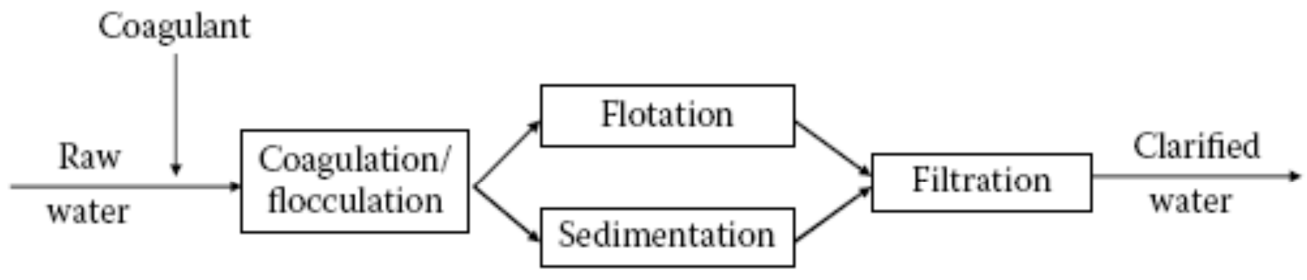

Figure 11. Typical order of processes for particle separation in a water treatment plant [14].

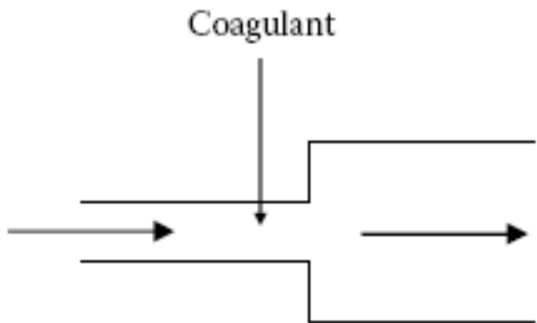

(a)

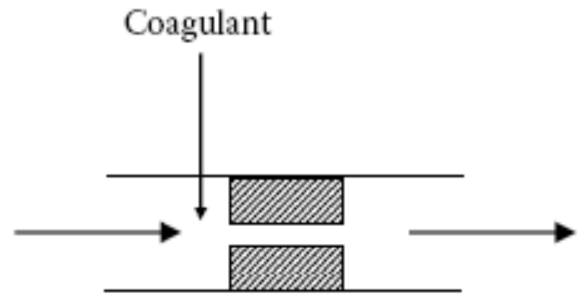

(b)

Figure 12. Rapid mixing of coagulant by "in-pipe" methods [(a) widening pipe; (b) narrowing pipe] [14]Even if rapid mixing has long been established to have significant actions on flocculation phenomena and has been examined in some detail, it is possible that many examples of poor efficiency of practical flocculation units can be related to poor mixing [14,28].

For the second step, some form of fluid motion has to be formed, which may be by mechanical stirring or flow (or both) $[14,51]$.

\subsubsection{Rapid Mixing}

Mixing is necessary to help coagulant addition to disturb stability in the colloidal system [5]. For particles to aggregate they must collide, and mixing develops collision [15]. Brownian movement, the random motion affected to small particles by bombardment by individual water molecules, is always detected as a natural mixing force [52]. Nevertheless, additional mixing energy is required [53]. High intensity mixing, which distributes the coagulant and generates rapid collisions, is most performant [16]. The frequency and number of particle collisions are also significant in coagulation [15]. In a low turbidity water, the introduction of solids such as clay or the recycle of previously settled solids may be indispensable to augment the number of particle collisions [16]. Rapid mixing (sometimes called "flash mixing") is required to distribute the coagulant species among the particles in as short a period as possible [53]. In the case of coagulants that adsorb on particles and neutralise their charge, this can be significant [54]. Poor mixing can conduct to local overdosing of coagulant and consequently restabilisation of some particles [53]. For this cause, a short time of intense, turbulent mixing is preferable [55]. The high shear rates related to rapid mixing can also have an important role in the transport of coagulant species and can augment the rate of adsorption [53]. In the case of hydrolysing metal coagulants, upon conditions where hydroxide precipitation and $S F$ are significant, the action of rapid mixing is not so obvious [44]. Nevertheless, it is established that hydrolysis rates are rapid and it is possible that rapid mixing conditions have some action in determining the 
relative rates of key processes such as adsorption and the formation of precipitates [52]. In principle, rapid mixing requires to be strong but of short period (i.e., few seconds) [53]. Otherwise, the nature of flocs generated subsequently can be influenced [23]. Prolonged times of intense mixing can conduct to the growth of small, compact flocs that grow slowly when the shear rate is decreased [55]. Rapid mixing may be realised in a flow-through stirred tank (a "backmix" reactor), even if this is an inefficient mixing device due to short-circuiting of flow [53]. It is not easy to achieve total and homogeneous distribution of introduced coagulant in a short period (i.e., less than one second) [54]. It is more frequent to inject coagulant at a point where there are turbulent conditions due to flow. This point may be in a channel - for example, where water flows over a weir - or in some kind of "in-pipe" mixer [56]. The latter way can implicate injecting coagulant at a point where the pipe either widens or narrows, as illustrated schematically in Fig. 12 [14].

\subsubsection{Floc Formation}

Frequently, growth of large flocs needs the application of velocity gradients or shear [57]. The major effects on flocculation rate are the particle (floc) size and content and the effective shear rate, $G$ [58]. Higher shear rates generate improved particle collision rate but may decrease collision efficiency and provoke certain floc breakage [17]. A helpful compromise is a process known as taper flocculation, in which the effective shear rate is initially high, producing a rapid flocculation rate, and then progressively decreased so that large flocs can generate [23]. Practically, application of shear implicates the introduction of energy [59]. This can be realised in two manners: mechanical or hydraulic. Mechanical devices are typified by flow-through stirred tanks of different types, often known as paddle flocculators [60]. The paddles may rotate about vertical or horizontal axes, but in all conditions the power input to the water is a function of the drag force on the paddle and the rotation speed. The power introduction to the water could be theoretically evaluated, but it is not too hard to evaluate [14].

\subsection{Enhanced Coagulation}

Halogenated organics are generated if natural organic matter (NOM) enters in reaction with free chlorine or free bromine [61]. Free chlorine is frequently added to water directly as a primary or secondary disinfectant [62]. Free bromine is produced from the oxidation by chlorine of the bromide ion in the source water. Factors influencing the generation of these halogenated disinfection by-products (DBPs) comprise type and concentration of NOM, chlorine form and dose, time, bromide ion concentration, $\mathrm{pH}$, organic nitrogen concentration, and temperature [63-65]. Because water treatment plants have been asked to control for total trihalomethans in the past, water treatment operators are likely familiar with some of the requirements that the Disinfectant/Disinfection By-Product (D/DBP) Rule implicate [66]. The main points of the DBP Rule and some of the main changes water supply systems are asked to satisfy with are published in literature [28]. Nevertheless, The D/DBP
Rule imposes the utilisation of enhanced coagulation (EC) treatment for the removal of DBP precursors for surface water systems that have decantation capabilities [67]. The enhanced process implicates changes to the existing coagulation process such as augmenting the coagulant injection, decreasing the $\mathrm{pH}$, or both sometimes [68-77].

Some authors [28] conducted bench, pilot, and demonstration scale studies to investigate arsenate removals during EC. The EC conditions in these researches comprised an augmentation of alum and ferric chloride coagulant injection from 10 to $30 \mathrm{mg} \mathrm{L}^{-1}$, a reduction of a $\mathrm{pH}$ from 7 to 5.5 , or both [28]. Results from these investigations established the following:

1. More than $90 \%$ arsenate removal can be realised upon EC conditions. Arsenate reductions above 90\% were easily realised upon all conditions when ferric chloride was utilised.

2. EC using ferric salts is more performant for arsenic removal than EC using alum. With an influent arsenic content of $5 \mu \mathrm{g} \mathrm{L}^{-1}$, ferric chloride realised $96 \%$ arsenate reduction with an injection of $10 \mathrm{mg} \mathrm{L}^{-1}$ and no acid introduction. When alum was utilised, $90 \%$ arsenate reduction could not be realised without decreasing the $\mathrm{pH}$.

3. Reducing $\mathrm{pH}$ during $\mathrm{EC}$ increased arsenic removal by alum coagulation. With ferric coagulation, $\mathrm{pH}$ does not play an important role between 5.5 and 7.0 [28].

Nevertheless, post-treatment $\mathrm{pH}$ adjustment may be needed for corrosion control when the process is realised at a low $\mathrm{pH}$ [28].

\section{Conclusions}

The main conclusions can be summarised as follow:

1. Brownian movement, the random motion related to small particles by bombardment by individual water molecules, is always present as a natural mixing force. Even if rapid mixing has long been established to have great roles on flocculation phenomena and has been investigated at a certain level, it is possible that many examples of poor efficiency of practical flocculation units can be related to poor mixing.

2. $S F$ conducts to faster agglomeration than $\mathrm{CN}$ and produces stronger and larger flocs: the generation of a hydroxide precipitate produces a big augmentation in the efficient particle concentration and so a greater collision rate. Hydroxide precipitates are generated from large numbers of colloids, which constitute very soon after injection. The flocs generated upon "sweep" conditions are also stronger and hence grow larger for the same shear conditions.

\section{Acknowledgements}

The present research work was undertaken by the Binladin Research Chair on Quality and Productivity Improvement in the Construction Industry funded by the Saudi Binladin Constructions Group; this is gratefully acknowledged. The opinions and conclusions presented in this paper are those of the authors and do not necessarily reflect the views of the sponsoring organisation. 


\section{References}

[1] L. Rizzo, A. Di Gennaro, M. Gallo, V. Belgiorno, Coagulation/chlorination of surface water: A comparison between chitosan and metal salts, Sep. Purif. Technol. 62 (2008) 79-85.

[2] O.S. Amuda, I.A. Amoo, Coagulation/flocculation process and sludge conditioning in beverage industrial wastewater treatment, J. Hazard. Mater. 141 (2007) 778-783.

[3] J.H. Masliyah, S. Bhattacharjee, Electrokinetic and colloid transport phenomena, John Wiley \& Sons, Inc., New Jersey, 2006.

[4] R.M. Pashley, M.E. Karaman, Applied colloid and surface chemistry, John Wiley \& Sons Ltd, Chichester, England, 2004.

[5] J.E. Smith, Jr., R.C. Renner, B.A. Hegg, J.H. Bender, Upgrading existing or designing new drinking water treatment facilities, Noyes Data Corporation, New Jersey, 1991.

[6] A. Szyguła, E. Guibal, M.A. Palacín, M. Ruiz, A.M. Sastre, Removal of an anionic dye (Acid Blue 92) by coagulation-flocculation using chitosan, J. Environ. Manag. 90 (2009) 2979-2986.

[7] A. Rushton, A.S. Ward, R.G. Holdich, Solid-liquid filtration and separation technology, VCH, Weinheim, 1996.

[8] A.P.Sr. Sincero, G.A. Sincero, Physical-chemical treatment of water and wastewater, IWA Publishing \& CRC Press, Boca Raton, 2003.

[9] F. Woodard, Industrial waste treatment handbook, Butterworth-Heinemann, Boston, 2001.

[10] W. Pietsch, Size enlargement by agglomeration, John Wiley \& Sons Ltd, Chichester, UK, 1991.

[11] J.T. O'Connor, T. O'Connor, R. Twait, Water treatment plant performance evaluations and operations, John Wiley \& Sons, Inc., New Jersey, 2009.

[12] S.A. Parsons, B. Jefferson, Introduction to potable water treatment processes, Blackwell Publishing Ltd, Oxford, UK, 2006.

[13] W. Lick, Sediment and contaminant transport in surface waters, IWA Publishing, CRC Press, Taylor \& Francis Group, LLC, Boca Raton, 2009.

[14] J. Gregory, Particles in water, properties and processes, CRC Press (Taylor \& Francis), Boca Raton, 2006.

[15] P. Dolejs, Considerations of the collision efficiency factor in coagulation of dissolved natural organic matter, In: Natural Organic Matter in Drinking Water, Origin, Characterization, and Removal, Workshop Proceedings, September 19-22, 1993, Chamonix, France, AWWA Research Foundation, USA, 165-172, 1994.

[16] D.N. Thomas, S.J. Judd, N. Fawcett, Flocculation modelling: A review, Water Res. 33 (1999) 1579-1592.

[17] E. Sharp, Natural organic matter coagulation, $\mathrm{PhD}$ thesis, School of Water Sciences, Cranfield University, Cranfield, UK, 2005.

[18] M.C. Sterling Jr., J.S. Bonner, A.N.S. Ernest, C.A. Page, R.L.
Autenrieth, Application of fractal flocculation and vertical transport model to aquatic sol-sediment systems, Water Res. 39 (2005) 1818-1830.

[19] R.E. Weiner, R.A. Matthews, Environmental engineering, 4th Ed., Butterworth-Heinemann, New York, 2003.

[20] R.W. Crites, J. Middlebrooks, S.C. Reed, Natural wastewater treatment systems, CRC Press (Taylor \& Francis), Boca Raton, 2006.

[21] K. Sutherland, Filters and filtration handbook, 5th Ed., Butterworth-Heinemann, Elsevier, Oxford, UK, 2008.

[22] T. Li, Z. Zhu, D. Wang, C. Yao, H. Tang, Characterization of floc size, strength and structure under various coagulation mechanisms, Powder Technol. 168 (2006) 104-110.

[23] M.I. Aguilar, J. Sáez, M. Lloréns, A. Soler, J.F. Ortuño, V. Meseguer, A. Fuentes, Improvement of coagulation-flocculation process using anionic polyacrylamide as coagulant aid, Chemosphere 58 (2005) 47-56.

[24] D.L. Russell, Practical wastewater treatment, John Wiley \& Sons, New Jersey, 2006.

[25] X. Wu, X. Ge, D. Wang, H. Tang, Distinct coagulation mechanism and model between alum and high Al13-PACl, Colloids Surf. A: Physicochem. Eng. Aspects 305 (2007) 89-96.

[26] P. Cañizares, F. Martínez, C. Jiménez, C. Sáez, M.A. Rodrigo, Coagulation and electrocoagulation of oil-in-water emulsions, J. Hazard. Mater. 151 (2008) 44-51.

[27] J.-M. Siéliéchi, B.S. Lartiges, G.J. Kayem, S. Hupont, C. Frochot, J. Thieme, J. Ghanbaja, J.B. d'Espinose de la Caillerie, O. Barrès, R. Kamga, P. Levitz, L.J. Michot, Changes in humic acid conformation during coagulation with ferric chloride: Implications for drinking water treatment, Water Res. 42 (2008) 2111-2123.

[28] F.R. Spellman, Handbook of water and wastewater treatment plant operations, Lewis Publishers (CRC Press), Boca Raton, 2003.

[29] E. R. Alley, Water quality control handbook, 2nd Ed., McGraw-Hill, New York, 2007.

[30] S.P. Chesters, E.G. Darton, S. Gallego, F.D. Vigo, The safe use of cationic flocculants with reverse osmosis membranes, Desalin. Water Treat. 6 (2009) 144-151.

[31] The Nalco water handbook, 2nd Ed., F.N. Kemmer (Ed.), McGraw-Hill, New York, 1988.

[32] Y. Zeng, J. Park, Characterization and coagulation performance of a novel inorganic polymer coagulant-Poly-zinc-silicate-sulfate, Colloids Surf. A: Physicochem. Eng. Aspects 334 (2009) 147-154.

[33] I. Ivancev-Tumbas, B. Dalmacija, Effects of coagulation processes on aldehydes formation in groundwater treated with common oxidative agents, Water Res. 35 (2001) 3950-3958.

[34] A.I. Zouboulis, P.A. Moussas, F. Vasilakou, Polyferric sulphate: Preparation, characterisation and application in coagulation experiments, J. Hazard. Mater. 155 (2008) 459-468.

[35] S. Suarez, J.M. Lema, F. Omil, Pre-treatment of hospital wastewater by coagulation-flocculation and flotation, Biores. Technol. 100 (2009) 2138-2146. 
[36] N.K. Shammas, Coagulation and flocculation (ch. 4), In: Physicochemical treatment processes (vol. 3), Handbook of environmental engineering, L.K. Wang, Y.-T. Huang, N.K. Shammas (Eds.), Humana Press Inc, New Jersey, 2005.

[37] C. Ye, D. Wang, B. Shi, J. Yu, J. Qu, M. Edwards, H. Tang, Alkalinity effect of coagulation with polyaluminum chlorides: Role of electrostatic patch, Colloids Surf. A: Physicochem. Eng. Aspects 294 (2007) 163-173.

[38] X. Xu, S. Yu,W. Shi, Z. Jiang, C. Wu, Effect of acid medium on the coagulation efficiency of polysilicate-ferric (PSF)-A new kind of inorganic polymer coagulant, Sep. Purif. Technol. 66 (2009) 486-491.

[39] B. Shi, G. Li, D. Wang, C. Feng, H. Tang, Removal of direct dyes by coagulation: The performance of preformed polymeric aluminum species, J. Hazard. Mater. 143 (2007) 567-574.

[40] X. Ntampou, A.I. Zouboulis, P. Samaras, Appropriate combination of physico-chemical methods (coagulation/flocculation and ozonation) for the efficient treatment of landfill leachates, Chemosphere 62 (2006) $722-730$.

[41] A.T. Owen, P.D. Fawell, J.D. Swift, D.M. Labbett, F.A. Benn, J.B. Farrow, Using turbulent pipe flow to study the factors affecting polymer-bridging flocculation of mineral systems, Intern. J. Mineral Process. 87 (2008) 90-99.

[42] C.E. Capes, Particle size enlargement (vol. 1), In: Handbook of powder technology, J.C. Williams, T. Allen (Eds.), Elsevier, Amsterdam, 1980.

[43] D. Bouyer, C. Coufort, A. Liné, Z. Do-Quang, Experimental analysis of floc size distributions in a 1-L jar under different hydrodynamics and physicochemical conditions, J. Colloid Interface Sci. 292 (2005) 413-428.

[44] J. De Zuane, Handbook of drinking water quality, 2nd Ed., John Wiley \& Sons, Inc., New York, 1997.

[45] F. Xiao, J. Ma, P. Yi, J.-C.H. Huang, Effects of low temperature on coagulation of kaolinite suspensions, Water Res. (2008) 2983-2992.

[46] F. Xiao, X. Zhang, J. Ma, Indecisiveness of electrophoretic mobility determination in evaluating $\mathrm{Fe}(\mathrm{III})$ coagulation performance, Sep. Purif. Technol. 68 (2009) 273-278.

[47] C.A. Walker, J.T. Kirby, S.K. Dentel, The streaming current detector: A quantitative model, J. Colloid Interface Sci. 182 (1996) 71-81.

[48] M. Kobayashi, Breakup and strength of polystyrene latex flocs subjected to a converging flow, Colloids Surf. A: Physicochem. Eng. Aspects 235 (2004) 73-78.

[49] A.M. Goula, M. Kostoglou, T.D. Karapantsios, A.I. Zouboulis, The effect of influent temperature variations in a sedimentation tank for potable water treatment - A computational fluid dynamics study, Water Res. 42 (2008) 3405-3414.

[50] A.L. Ahmad, S.S. Wong, T.T. Teng, A. Zuhairi, Improvement of alum and PACl coagulation by polyacrylamides (PAMs) for the treatment of pulp and paper mill wastewater, Chem. Eng. J. 137 (2008) 510-517.

[51] O.P. Prat, J.J. Ducoste, Simulation of flocculation in stirred vessels, Lagrangian versus Eulerian, Trans IChemE 85 (2007) 207-219.
[52] C. Coufort, D. Bouyer, A. Liné, B. Haut, Modelling of flocculation using a population balance equation, Chem. Eng. Process. 46 (2007) 1264-1273.

[53] P. Mavros, Flow visualization in stirred vessels: A review of experimental techniques, Trans IChemE 79 (2001) 113-127.

[54] H.-C. Kim, S. Lee, Pump diffusion flash mixing (PDFM) for improving coagulation process in drinking water treatment, Sep. Purif. Technol. 52 (2006) 117-125.

[55] A. Maes, S. Vreysen, N.N. Rulyov, Effect of various parameters on the ultraflocculation of fine sorbent particles, used in the wastewater purification from organic contaminants, Water Res. 37 (2003) 2090-2096.

[56] R.K. Thakur, Ch. Vial, K.D.P. Nigam, E.B. Nauman, G. Djelveh, Static mixers in the process industries - A review, Trans IChemE 81 (2003) 787-826.

[57] G.L. McConnachie, G.K. Folkard, M.A. Mtawali, J.P. Sutherland, Field trials of appropriate hydraulic flocculation processes, Water Res. 33 (1999) 1425-1434.

[58] S.A.A. Tabatabai, M.D. Kennedy, G.L. Amy, J.C. Schippers, Optimizing inline coagulation to reduce chemical consumption in MF/UF systems, Desalin. Water Treat. 6 (2009) 94-101.

[59] M. Zeidan, B.H. Xu, X. Jia, R.A. Williams, Simulation of aggregate deformation and breakup in simple shear flows using a combined continuum and discrete model, Trans IChemE 85 (2007) 1645-1654.

[60] C. Coufort, D. Bouyer, A. Liné, Flocculation related to local hydrodynamics in a Taylor-Couette reactor and in a jar, Chem. Eng. Sci. 60 (2005) $2179-2192$.

[61] D.A. Reckhow, G. Makdissy, P.S. Rees, Disinfection by-product precursor content of natural organic matter extracts (ch. 6), In: Disinfection by-products in drinking water, occurrence, formation, health effects, and control, T. Karanfil, S.W. Krasner, P. Westerhoff, Y. Xie, (Eds.), ACS Symposium Series 995, ACS, Washinton, 2008.

[62] D. An, J. Song, W. Gao, G. Chen, N. Gao, Molecular weight distribution for NOM in different drinking water treatment processes, Desalin. Water Treat. 5 (2009) 267-274.

[63] Y.F. Xie, Disinfection by-products in drinking water, formation, analysis, and control, CRC Press LLC, Boca Raton, 2004.

[64] C.W.K. Chow, J.A. van Leeuwen, R. Fabris, M. Drikas, Optimised coagulation using aluminium sulfate for the removal of dissolved organic carbon, Desalination 245 (2009) 120-134.

[65] J. Kim, Fate of THMs and HAAs in low TOC surface water, Environ. Res. 109 (2009) 158-165.

[66] H. Wong, K.M. Mok, X.J. Fan, Natural organic matter and formation of trihalomethanes in two water treatment processes, Desalination 210 (2007) 44-51.

[67] T. Karanfil, S.W. Krasner, P. Westerhoff, Y. Xie, Recent advances in disinfection by-product formation, occurrence, control, health effects, and regulations (ch. 1), In: Disinfection by-products in drinking water, occurrence, formation, health effects, and control, T. Karanfil, S.W. Krasner, P. Westerhoff, Y. Xie, (Eds.), ACS Symposium Series 995, ACS, Washinton, 2008.

[68] USEPA (US Environmental Protection Agency), Enhanced coagulation and enhanced precipitative softening guidance manual, Office of water (4607), EPA 815-R-99-012, May 1999. 
[69] D. Ghernaout, B. Ghernaout, A. Kellil, Natural organic matter removal and enhanced coagulation as a link between coagulation and electrocoagulation, Desalin. Water Treat. 2 (2009) 203-222.

[70] D. Ghernaout, D. Ghernaout, A. Saiba, Algae and cyanotoxins removal by coagulation/flocculation: A review, Desalin. Water Treat. 20 (2010) 133-143.

[71] D. Ghernaout, S. Moulay, N. Ait Messaoudene, M. Aichouni, M.W. Naceur, A. Boucherit, Coagulation and chlorination of NOM and algae in water treatment: A review, Intern. J. Environ. Monitor. Analys. 2 (2014) 23-34.

[72] D. Ghernaout, B. Ghernaout, M.W. Naceur, Embodying the chemical water treatment in the green chemistry-A review, Desalination 271 (2011) 1-10.

[73] D. Ghernaout, The hydrophilic/hydrophobic ratio vs. dissolved organics removal by coagulation - A review, J. King Saud Univer. - Sci. 26 (2014) 169-180.
[74] D. Ghernaout, The best available technology of water/wastewater treatment and seawater desalination: Simulation of the open sky seawater distillation, Green Sustain. Chem. 3 (2013) 68-88.

[75] D. Ghernaout, B. Ghernaout, On the concept of the future drinking water treatment plant: algae harvesting from the algal biomass for biodiesel production - a review, Desalin. Water Treat. 49 (2012) 1-18.

[76] D. Ghernaout, B. Ghernaout, Sweep flocculation as a second form of charge neutralisation - a review, Desalin. Water Treat. 44 (2012) 15-28.

[77] O. Bello, Y. Hamam, K. Djouani, Control of a coagulation chemical dosing unit for water treatment plants using MMPC based on fuzzy weighting, J. Water Process Engin. 4 (2014) 34-46. 